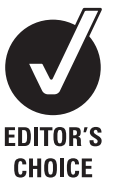

CHOICE

PAPER

\title{
Threats and offers in community mental healthcare
}

\author{
Michael Dunn,' Daniel Maughan, ${ }^{2}$ Tony Hope, ${ }^{1}$ Krysia Canvin, ${ }^{3}$ Jorun Rugkåsa, ${ }^{3}$ \\ Julia Sinclair, ${ }^{4}$ Tom Burns ${ }^{3}$
}

${ }^{1}$ The Ethox Centre, University of Oxford, Oxford, UK

${ }^{2}$ Oxford Health NHS Foundation Trust, Oxford, UK

${ }^{3}$ Department of Psychiatry, University of Oxford, Oxford, UK ${ }^{4}$ School of Medicine, University of Southampton, Southampton, UK

\section{Correspondence to}

Dr Michael Dunn, The Ethox Centre, University of Oxford, Old Road Campus, Headington, Oxford OX3 7LF, UK: michael.dunn@ethox.ox.ac.uk

Received 3 August 2011 Revised 10 October 2011 Accepted 23 October 2011 Published Online First

2 December 2011

\section{ABSTRACT}

Making threats and offers to patients is a strategy used in community mental healthcare to increase treatment adherence. In this paper, an ethical analysis of these types of proposal is presented. It is argued (1) that the primary ethical consideration is to identify the professional duties of care held by those working in community mental health because the nature of these duties will enable a threat to be differentiated from an offer, (2) that threatening to act in a way that would equate with a failure to uphold the requirements of these duties is wrong, irrespective of the benefit accrued through treatment adherence and (3) that making offers to patients raises a number of secondary ethical considerations that need to be judged on their own merit in the context of individual patient care. The paper concludes by considering the implications of these arguments, setting out a pathway designed to assist community mental healthcare practitioners to determine whether making a specific proposal to a patient is right or wrong.

\section{INTRODUCTION}

Mental healthcare practitioners use a range of formal and informal tools to increase patients' adherence to treatment. In making sense of the different ways in which treatment adherence can be increased in mental health, Szmukler and Appelbaum have proposed a hierarchy of treatment pressures that ranges from persuasion, leverage, inducements and threats, to the use of compulsion. ${ }^{1-3}$ Szmukler and Appelbaum differentiate these pressures on the basis of the morally salient distinctions between them, which can be identified using conceptual and ethical analysis.

In this paper, we focus on threats and offers made to patients by practitioners for the purpose of improving adherence to treatment in the context of community mental healthcare. By community mental healthcare we are referring to mental health services that are provided to patients outside an acute psychiatric hospital. The nature and scope of community mental health services vary markedly between countries, but will broadly reflect different psychiatric specialties and will involve the provision of services to patients with a range of different conditions. Examples of the proposals we are examining include enabling or removing access to community services, visiting rights for children, access to supported housing placements, specialist help with welfare payments, access to hobbies and social activities, and providing financial rewards.
Evidence suggests that practitioners and patients consider such threats and offers to be ethically problematic because they are coercive, or involve treating patients unfairly. ${ }^{4-7}$ We propose a framework for making ethical judgements about these proposals. This framework places professional duties of care, rather than coercion, as the primary consideration. We intend this framework to be of practical guidance in deciding whether a specific proposal is, or is not, ethically acceptable.

\section{THE NATURE AND SCOPE OF THREATS AND OFFERS}

The threats and offers that concern us involve a healthcare practitioner threatening to remove support if the patient does not adhere to treatment, or making an offer to provide support only if the patient does adhere to treatment. Most commonly, threats and offers take the form of a bi-conditional proposal (Szmukler and Appelbaum, p235) ${ }^{1}$ : if the patient does $\mathrm{X}$, then the clinician/service will do $\mathrm{Y}$; or if the patient does not do $\mathrm{X}$, then the clinician/ service will not do $\mathrm{Y}$ (or will do Z).

For proposals of this form to be effective, the patient must have something to lose or gain that she values and accepting (or not accepting) the proposal must affect whether that loss or gain is realised. A threat or offer will be credible if the patient perceives the practitioner as having the power to act on the proposal. ${ }^{8}$

Empirical studies show that threats and offers of this form are used to increase treatment adherence, particularly among patients with enduring mental health problems who have experienced repeated hospitalisations, intensive outpatient service use and who display more severe, disabling and longer-lasting psychopathology. $^{7}$ 9-13

In considering whether making such a proposal is right or wrong on ethical grounds, we argue that the first question is to determine whether the proposal is a threat or an offer.

\section{DISTINGUISHING THREATS FROM OFFERS}

Contemporary accounts of the distinction between threats and offers centre around Wertheimer's claim that a threat should be understood in terms of a proposal which, if not accepted, leads to a person 'being made worse off' compared with a relevant pre-proposal baseline. ${ }^{8}$ Offers, if not accepted, leave people no worse off compared with that baseline. On such an account, threats reduce the range of options available compared with the pre-proposal baseline, while offers expand that range. 
Crucial to this account of threats and offers is the pre-proposal baseline. A patient who is told that contact with her children will be removed if she does not sign up to a treatment plan has had her options reduced compared with the pre-proposal situation. This proposal looks to be a threat. A patient who is told that she will receive a financial reward if she complies with treatment is given an option in addition to those available in the pre-proposal situation. This proposal looks to be an offer.

\section{THE PRE-PROPOSAL BASELINE}

The picture becomes more complex, however, when this preproposal baseline is defined. Two broad approaches have been taken: to understand the baseline in empirical terms and to understand the baseline in normative terms. An empirical approach-at least in its 'statistical' form ${ }^{8}{ }^{14}$-asks what, as a matter of fact, was the baseline. A normative approach asks what it should have been. ${ }^{8} 15$

If a patient is denied access to her children, a proposal that access be restored on condition of her adhering to treatment would, on the empirical approach, be judged to be an offer because, as a matter of fact, the patient had no access at the time of the proposal. On the normative approach, however, the proposal would be judged to be a threat, if there are good reasons for concluding that it was wrong to deny access to her children in the first place. Having such access is the pre-proposal baseline, so the proposal is a threat because access ought to be facilitated independently of the proposal. Since we are considering what health professionals should do, it is the normative approach that is relevant to our argument.

\section{THE RIGHTS-VIOLATION ACCOUNT OF THE PRE-PROPOSAL BASELINE}

The dominant approach has been to substantiate the normative account of the pre-proposal baseline within an ethical theory based upon individuals' rights. ${ }^{816}$ A threat on this account is one in which X proposes to violate Y's rights and the wrong of such a threat involves making treatment adherence contingent on a course of action that violates a patient's rights.

Bonnie and Monahan ${ }^{17}$ endorse this position in the context of community mental healthcare. They argue that examining how the law interprets the scope of an individual's rights sets the preproposal baseline and determines whether, for example, making a proposal that involves, if not accepted, withholding disability benefits or restricting access to housing, is, or is not, a threat. We believe that this account of the baseline in terms of legal rights is mistaken in this context because the nature of the obligations that practitioners have towards their patients is not captured solely by such a notion of rights.

\section{THE DUTIES OF CARE ACCOUNT OF THE PRE-PROPOSAL BASELINE}

We propose that a broader focus on professional duties of care, rather than patients' legal rights, offers a better foundation for determining the pre-proposal baseline in community mental healthcare. On this account, determining which proposals are threats requires a prior understanding of the nature of these duties and how they ought to be applied in the care of individual patients. When a practitioner proposes to fulfil the duties she owes to a patient only if that patient adheres to treatment, this proposal is a threat. In contrast, when a practitioner proposes to extend a patient's range of options beyond the scope of the duties owed to the patient, on condition that the patient adheres to treatment, the proposal is an offer.
An account of the pre-proposal baseline based on the duties of care owed to patients is more generous to patients than one based solely on rights. Of course, in an account in which rights are understood as derived from corresponding duties, there will be no difference between a rights- and a duties-based account of the pre-proposal baseline. But most accounts of rights, including those assumed in Bonnie and Monahan's analysis, are more limited in scope than are duties of care. In the context of community mental healthcare, we are arguing, these rights (or, at any rate, the pre-proposal baseline) should be grounded in the concept of a duty of care. Community mental healthcare practitioners will have duties of care to their patients that reflect different kinds of obligation. In part, these obligations will be legal in nature (which are the focus of Bonnie and Monahan's analysis), but they will also include the broader ethical and professional obligations that are derived from moral theoretical considerations and the requirements of the professional bodies regulating the standards of community mental health practice, respectively.

\section{DUTIES OF CARE ARE CONTEXT-DEPENDENT}

Because the duties of healthcare providers towards patients reflect ethical, legal and professional obligations, these duties are highly context-dependent and will differ in different services, and also between patients in the same service. Thus, determining whether a proposal is a threat or an offer is also contextdependent. Practitioners will need to address two issues in order to judge whether a particular proposal is a threat or an offer. The first issue is to clarify the duties that they have towards patients in general. This will be a significant challenge; the requirements of the ethical values that give shape to these duties are uncertain, demonstrated by ongoing debates about how to respect personal autonomy in mental healthcare interventions, ${ }^{18}{ }^{19}$ or how benefit ought to be conceived in defining models of good practice. ${ }^{2021}$ In some difficult cases, the broad ethical obligations that are identified as giving shape to the duties of care might conflict with the legal or professional standards governing practitioners' work.

The second issue is to determine how these duties apply to the care of individual patients. This will involve translating the general duties that practitioners have towards their patients into services that reflect different institutional and therapeutic traditions. It will also require these general duties to be tailored to the identified and specific needs of individual patients. Determining the duties of care towards the individual patient must, on our account, precede the classification of a proposal as either a threat or an offer.

Since duties are context-dependent, the same proposal may be an offer for one patient and a threat for another. Consider the proposal by a psychiatric nurse to take a patient with the negative symptoms of schizophrenia of poor motivation and social withdrawal to a social event at the community centre only if she agrees to continue to take her medication. This proposal would be a threat if it is identified that the service has a duty to enable that patient to attend the event as part of the treatment package to address her negative symptoms. For another patient with schizophrenia who is currently stable and does not have these negative symptoms of her illness, the patient might value attending the social event, but, as this value is independent of the treatment that the service has a duty of care to provide, there is no obligation for the service to facilitate such an activity. Therefore, the nurse's proposal to take this second patient to the social event on condition she agrees to take medication would be an offer rather than a threat. 


\section{THREATS ARE WRONG}

To recap: our suggestion is that threats and offers can be distinguished by clarifying the professional duties that ought to be applied in relation to the care of individual patients within a community mental health service. Therefore, when a practitioner is considering whether a particular proposal is ethically acceptable or not, the first step is to clarify, independently of the proposal, what duties she owes to the patient. This clarification should normally be part of clinical practice and is where the normative work is done.

If identified as a threat, it would not be ethically acceptable for the proposal to be made. This is because if it is wrong for a practitioner (or service) to act in ways that fail to uphold professional duties (when elaborated correctly), it is also wrong to make a proposal to a patient that meets our criteria for that proposal being a threat. There is, of course, a certain circularity in this argument, but it does, nevertheless, have both practical and conceptual value. If identified as an offer, there are further ethical considerations to be examined before a judgement can be made. We discuss these further considerations in turn.

\section{FOUR CONSIDERATIONS IN JUDGING THE ETHICAL STATUS OF AN OFFER \\ Does the offer involve treating patients unwisely?}

The first consideration is that an offer may involve treating patients unwisely and, in particular, that the offer may have significant unwanted negative consequences. These negative consequences might be for the individual patient, or for other patients. Materially advantaging a patient to encourage treatment adherence could bring short-term benefits but have negative effects in the long term. The evaluation of consequences as positive or negative depends on the model of mental healthcare that is drawn upon to substantiate the professional duty to benefit patients. For example, within a 'recovery model' of mental healthcare, a reward could be judged to undermine the patient's development of personal responsibility in the journey towards recovery. ${ }^{22}$

Alternatively, an offer might benefit the individual patient, but might have negative consequences for other patients. For example, providing an inducement to a patient to encourage treatment adherence might lead other patients, when hearing of this, to stop taking their medication unless they were given a similar inducement.

Offers may, in addition, lead to fundamental changes in the way practitioners see the role of treatment, leading to their abandoning a belief in the possibility of progress. The resultant disillusionment in benefiting patients could have further effects for all patients within a service. Whether this form of 'therapeutic nihilism'23 would in fact develop through making offers to patients is an empirical question that deserves closer scrutiny.

\section{Does the offer involve exploiting patients?}

The second consideration is that offers may exploit patients. Exploitation, which can be defined broadly as a situation in which $\mathrm{X}$ takes unfair advantage of $\mathrm{Y}^{24}$ has been considered more in the contexts of research ethics, ${ }^{25} 26$ and the sale of human organs, ${ }^{27}$ than in clinical practice. Exploitation requires the exploiter to benefit unfairly, as is the case in the rare but clearcut examples of financial and sexual exploitation in clinical practice. Clearly, offers that benefit the practitioner and that involve such obvious abuse of a patient, are wrong.

However, when a practitioner is attempting to benefit a patient when considering whether to make her an offer, the key consideration from the point of view of exploitation is to clarify whether the practitioner is acting with the primary intention of benefiting herself. This benefit could operate at a systemic rather than personal level, such as when an offer is proposed as a means for a practitioner to meet targets for treatment adherence in order to avoid sanction by the employing organisation. Personal benefit might be relevant in offers used with the primary intention of guarding against reputational damage should the patient harm himself or others on stopping her medication.

The key point from the perspective of exploitation is that, when considering making an offer, the benefits to the practitioners should be identified and removed from the decision process, with the offer being proposed only if it is justified in the interests of the patient. There may be rare occasions when the benefit to the practitioners tips the balance in favour of making the offer, in which case that decision will need clear and explicit justification to demonstrate that it will not unfairly disadvantage patients.

\section{Does the offer raise broader questions of fairness?}

Szmukler ${ }^{2}$ has argued that an offer (eg, a payment) made to a patient in the situation where that patient has withdrawn from treatment may be unfair to those patients who adhere to treatment without benefiting from the offer. Thus, questions of fairness in relation to offers made to patients arise at the broader institutional and societal level, rather than solely in the context of individual patient-professional relationships. Determining whether the situation outlined by Szmukler is unfair depends on the view taken about patient responsibility in relation to treatment adherence. In a service which does not generally consider patients responsible for treatment adherence, the offer envisaged would not be ethically problematic on the grounds of being unfair. In a service that held patients responsible for their own recovery, however, whether on grounds of principle or as a therapeutic tool, such an offer might be unfair to patients who take medication without the inducement of the offer.

Considerations of unfairness also arise at the broader societal level of resource allocation. An offer using more resources than was justified given the overall resources available might, for that reason, be unfair. Such a justification could be fleshed out in terms of cost-effectiveness or need.

\section{Does the offer undermine the voluntariness of patients decision-making?}

Finally, there is intuitive appeal in the idea that an offer can, if sufficiently attractive, undermine the voluntariness of a patient's decision on the grounds that the offer is, in some way, irresistible. We disagree with this. Wertheimer distinguishes between situations in which a person acts non-volitionally from those when a person makes a decision under conditions of constrained volition. ${ }^{8}$ In the first situation the person has no choice to make, or is unable to make a choice. No proposal is made and the individual is either compelled to take a particular course of action (eg, through physical restraint or the forcible administration of medication), or is unable to understand the decision-making process. In neither case is the individual acting as a moral agent.

In contrast, in situations of constrained volition, a proposal is presented that has the effect of restricting a person's choices. Crucially, however, the person retains the ability to make a decision from the (limited) choices presented. Thus, even in the paradigmatic coercive threat, 'your money or your life', the 
person can decide not to hand over her money, remaining in charge of how she acts. ${ }^{28}$

As Mackie ${ }^{29}$ observes, actions made under duress, danger or temptation will at most complicate how these actions are described as intentional and "the only kind of compulsion that makes an act unintentional is simple physical compulsion or constraint, which really makes it not an act of this agent at all". We concur: the complexity-and concern-in making a proposal to a patient lies in the wrongfulness of any constraints the proposal places on her freedom, the negative consequences that would result from the proposal being accepted, the unfairness of the proposal to the patient or other patients, or the exploitative nature of the relationship between the parties involved. It does not lie in the failure to respect personal autonomy that would result from the proposal undermining the voluntariness of the patient's decision-making.

While we have suggested that the connection between threats and involuntary decision-making is open to challenge, other philosophers take quite the opposite position. They maintain that threats and offers can undermine the voluntariness of a person's decision-making because of their coercive force. The 'lecherous millionaire' case ${ }^{14}$ is often discussed in support of this claim. ${ }^{30}{ }^{31}$ Here, A's child will die without expensive surgery that she cannot afford and for which the state will not pay. B, a millionaire, offers to pay for the surgery if A becomes his mistress. Feinberg contends that B's offer manipulates A's options in such a way that A has no choice but to comply with the terms of the proposal in order to avoid an alternative that she finds unacceptable. While we agree that B's offer is ethically problematic, the wrong of B's manipulation of the choice options available to $\mathrm{A}$ is not captured by any interference by $\mathrm{B}$ on A's ability to make a decision between these choices. On our view, A remains able to decide whether she becomes B's mistress

Similarly, in Shakespeare's Measure for Measure, Isabella refuses to have sex with Angelo even though he offers to save her brother's life if she does so. "Better it were a brother died at once, than that a sister, by redeeming him, died forever... More than our brother is our chastity." (Act 2, Scene IV) is her response to Angelo's proposal. This response captures something important about the reason for rejecting the argument that proposals such as this can undermine voluntariness. It is precisely at times when our choices are restricted in some important way that the shape of the answers to the questions 'what do I want?', 'what do I value?', 'what is important to me?' are at the forefront of our minds and become most apparent to us. Thus, rather than being unable to resist making considered decisions in light of such offers, these offers require us to scrutinise, examine and develop our commitments, values and priorities in life.

We agree with other commentators that the wrong in the lecherous millionaire case and others should not be understood in terms of coercion, but rather in terms of B's exploitation of A. ${ }^{32}{ }^{33}$ In other words, this is a case of sexual exploitation, not one of coercion in which a person's decision-making is rendered involuntary.

In the context of community mental healthcare, the only consideration relevant to the voluntariness of the patient's decision to accept an offer is to ascertain whether the patient's psychopathology limits her agency. In the context of offers, this is an issue that will be relevant specifically to patients with drug dependencies, rather than those with long-term affective or psychotic illnesses. It is also a complex question and one on which there are many conflicting views. On the one hand, it is argued that 'internal influences' can render a person's action involuntary because such an action will not be intentional. This is because the action is causally determined by a desire over which the person has no effective control. ${ }^{34}$ On the other hand, it is argued that drug-orientated desires are formed in an identical way to regular desires and, therefore, that drug dependency does not impact on the voluntariness of action. ${ }^{35} 36$ Most importantly, for our argument here, is that, even if we accept the analysis of Nelson and colleagues, it is difficult to imagine a situation in which making an offer that the patient cannot decide to accept voluntarily would not constitute a breach in the duty of care (and that, accordingly, the offer ought to be identified as a threat).

Separate to the issue of voluntariness is the issue of the patient's decision-making capacity. While Szmukler and Appelbaum $^{1}$ consider decision-making capacity at length in their analysis of treatment pressures, it is unlikely that decisional capacity will be at issue in the types of offer we are considering. This is because these offers are being made specifically with the aim of influencing the patient's decision. It will be uncommon in clinical practice, therefore, for the patient to lack the capacity to decide whether or not to accept the offer.

\section{Do offers raise problems of value incommensurability?}

Szmukler ${ }^{2}$ has raised a further ethical issue: that offering financial rewards to encourage treatment adherence raises problems of value incommensurability. Recognising that resource allocation considerations mean that healthcare encounters are necessarily commodified, Szmukler identifies the incommensurable values as money and patients' competent decisions made in light of their considered interests. On his argument, it is wrong to offer money to patients because the intrinsic value of a patient making her own considered decision is incommensurate with such an instrumental value. By seeking to replace the value of a patient's considered decision with an incommensurable value, practitioners act wrongly because they fail to show due respect to that patient qua person.

There are two main objections to this argument. The first is to deny that the two values are incommensurate. We frequently weigh up different interests when making decisions in our lives and on many occasions such interests will reflect instrumental values. For example, the supermarket owner who makes a twofor-one offer may influence purchasing decisions but it would be incorrect to conclude that the value in a customer making her own decision had, in some way, been contaminated precisely because a weighing up of financial considerations could lie at the heart of the decision that she has made. The second objection is that, even were the values incommensurate, it does not follow that introducing an instrumental value into the decision-making process fails to show the patient respect. Indeed, if the effect of a decision to withdraw from treatment means that a patient requires increased levels of support in the future and becomes unable to act upon her interests, giving ethical primacy to a narrow, 'in-the-moment' refusal of treatment rather than the broader scope of the duties of care that shape the provision of treatment could itself be considered to fail to show due respect to the person.

\section{PRACTICAL IMPLICATIONS}

Our analysis of threats and offers can be summarised using a five-step framework. We hope this framework will be useful to practitioners in judging whether making a proposal to a patient is ethically justified or not. The general form of the proposal 
under consideration is: if the patient does $\mathrm{X}$, then the clinician/ service will do $\mathrm{Y}$; or if the patient does not do $\mathrm{X}$, then the clinician/service will not do Y (or will do Z).

\section{Step 1}

The first step is to decide whether the proposal is a threat or an offer. In distinguishing a threat from an offer it is necessary to clarify, independently of the proposal, what duties the service owes the particular patient. Establishing such duties is a general responsibility of health practitioners, teams and services. The duties will depend on how ethical values are interpreted and applied in practice and will vary between different mental healthcare systems, between services within a system and between different patients in a service.

Having established the duties of care, the key question is whether the proposal, if accepted, or not accepted, will lead to an outcome consistent with the practitioner having failed to act in line with these duties. If this is the case, then the proposal is a threat and should not be made. If this is not the case, then the proposal is an offer. If the proposal is an offer then further issues need to be considered before an ethical judgement is made (steps $2-5)$.

\section{Step 2}

Once a proposal has been identified as an offer, the second step asks: is the offer likely to be unwise? This question focuses particularly on consequences, both for the specific patient and for others. Although the offer might be of value to the patient in the short term, it may have longer-term detrimental effects for that patient, or detrimental effects on other patients.

\section{Step 3}

The third step asks: does the offer exploit the patient? The key consideration is whether there are benefits to the health professionals, or system, if the patient accepts the offer. In making the final judgement about the ethical status of the offer it will be important to separate benefits to the patient from benefits to the professionals and system.

\section{Step 4}

The fourth step asks: does the offer raise broader questions of fairness? At the micro level the question is whether the offer treats other patients in the relevant service fairly. At the macro level the question is whether the offer represents a good use of healthcare resources.

\section{Step 5}

The last step asks: does the offer compromise the voluntariness of the patient's decision-making? The main issue here is to ascertain if there is any way that the patient's psychopathology impacts upon on her agency such that her decision to accept the offer would not be a voluntary decision. The attractiveness of the offer per se (we have argued) does not affect voluntariness.

Having taken steps $2-5$, the ethical issues relevant to the decision as to whether it is right or not to make the offer should have been identified. The fact that there are ethical problems with the offer does not necessarily mean the offer is unethical. In the case of offers (as opposed to threats) the overall anticipated benefits of making the offer will need to be balanced against the ethical problems identified. Here, judgement is required.

This framework does not provide an algorithm, but it does provide practitioners with a practical tool for making decisions. Because the normative considerations that are salient within this framework are generally those with which practitioners are familiar-professional duties of care, foreseeable consequences and decision-making capacity-such a framework is likely to be useful for the practice of community mental healthcare. The judgements that need to be made require considerable understanding of the patient and they will often best be made after integrating information from several sources. The case conference might be an appropriate setting within which this framework is applied. However, it is important to recognise that this framework will need to be applied pragmatically in light of the evidence available and must be subject to continual reassessment as the contextual factors relevant to making judgements about each step within the framework change.

Acknowledgements The authors thank John McMillan for his invaluable comments on an earlier draft and the five anonymous reviewers for their helpful suggestions.

Funding NHS National Institute of Health Research (NIHR). Grant number RP-PG-0606-1006. The views expressed here are those of the authors and do not necessarily reflect those of the NIHR.

\section{Competing interests None.}

Patient consent The paper is theoretical and does not involve patients.

Contributors MD took the lead role in developing and drafting the paper. DM, TH were involved in the drafting process and offered critical reflection on the content of the paper. KC, JR were involved in the development of the paper and offered critical commentary on the content. JS, TB offered critical commentary on the content and revised parts of the paper

Provenance and peer review Not commissioned; externally peer reviewed.

\section{REFERENCES}

1. Szmukler G, Appelbaum PS. Treatment pressures, leverage, coercion and compulsion in mental health care. J Ment Health 2008;17:233-44.

2. Szmukler G. Financial incentives for patients in the treatment of psychosis. J Med Ethics 2009;35:224-8.

3. Szmukler G. 'Coercive' measures. In: Helmchen H, Sartorius N, eds. Ethics in Psychiatry: European Contributions. Dordrecht: Springer, 2010:321-40.

4. Elbogen EB, Swanson JW, Swartz MS. Psychiatric disability, the use of financial leverage and perceived coercion in mental health services. Int J Forensic Mental Health 2003;2:119-27.

5. Jaeger M, Rossler W. Enhancement of outpatient treatment adherence: patients' perceptions of coercion, fairness and effectiveness. Psychiatry Res 2010;180:48-53

6. Priebe S, Sinclair J, Burton A, et al. Acceptability of offering financial incentives to achieve medication adherence in patients with severe mental illness: a focus group study. J Med Ethics 2010;36:463-8.

7. Appelbaum PS, Redlich A. Use of leverage over patients' money to promote adherence to psychiatric treatment. J Nerv Ment Dis 2006;194:294-302.

8. Wertheimer A. Coercion. Princeton, NJ: Princeton University Press, 1987; $\mathbf{9 - 1 0 : 2 0 2 - 2 1 . ~}$

9. Redlich AD, Steadman HJ, Robbins PC, et al. Use of the criminal justice system to leverage mental health treatment: effects of treatment adherence and satisfaction. $J$ Am Acad Psychiatry Law 2006;34:292-9.

10. Monahan J, Redlich AD, Swanson J, et al. Use of leverage to improve adherence to psychiatric treatment in the community. Psychiatr Serv 2005;56:37-44.

11. Burns T, Yeeles K, Molodynski A, et al. Pressures to adhere to treatment ('leverage') in English mental health care. Br J Psychiatry 2011;199:145-50.

12. Angell B, Mahoney CA, Martinez NI. Promoting treatment adherence in assertive outreach treatment. Soc Serv Rev 2006;80:486-526.

13. Appelbaum P, Le Melle S. Techniques used by Assertive Community Treatment (ACT) teams to encourage adherence: patient and staff perspectives. Community Ment Health J 2008;44:459-64.

14. Feinberg J. The Moral Limits of the Criminal Law, Vol. 3: Harm to Self. New York: Oxford University Press, 1986:219-28.

15. Ryan CC. The normative concept of coercion. Mind 1980;89:481-98

16. Murphy JG. Consent, coercion and hard choices. Va Law Rev 1981;67:79-95

17. Bonnie RJ, Monahan J. From coercion to contract: reframing the debate on mandated community treatment for people with mental disorders. Law Hum Behav 2005;29:485-503.

18. Epright MC. Coercing future freedom: consent and capacities for autonomous choice. J Law Med Ethics 2010;38:799-806.

19. van Willigenburg T, Delaere PJJ. Protecting autonomy as authenticity using Ulysses contracts. J Med Philos 2005;30:395-409.

20. Ghaemi SN. The rise and fall of the biopsychosocial model. Br J Psychiatry 2009;195:3-4 
21. Ramon S, Healy B, Renouf N. Recovery from mental illness as an emergent concept and practice in Australia and the UK. Int J Soc Psychiatry 2007:53:108-22.

22. Pearce S, Pickard $H$. Finding the will to recover: philosophical perspectives on agency and the sick role. J Med Ethics 2010;36:831-3.

23. Starr P. The politics of therapeutic nihilism. Hastings Cent Rep 1976;6:24-30.

24. Wertheimer A. Exploitation. Princeton, NJ: Princeton University Press, 1996:207.

25. Resnik DB. Exploitation in biomedical research. Theor Med Bioeth 2003;24:233-59.

26. Wertheimer A. Exploitation in clinical research. In: Emanuel EJ, Grady C, Crouch RA, et al, eds. The Oxford Textbook of Clinical Research Ethics. Oxford: Oxford University Press, 2008:201-10.

27. Wilkinson S. Bodies for Sale: Ethics and Exploitation in the Human Body Trade. Abingdon: Routledge, 2003:9-26.

28. Carr CL. Coercion and freedom. Am Philos 0 1988;25:59-67.
29. Mackie JL. Ethics: Inventing Right and Wrong New York: Penguin 1977:206.

30. McGregor J. Undue influence as coercive offers in clinical trials. In: Reidy DA, Riker WJ, eds. Coercion and the State. New York: Springer, 2008:45-62.

31. McMillan J. Coercive offers and research participation: a comment on wertheimer and miller. J Med Ethics 2010;36:383-4.

32. Zimmerman D. Coercive wage offers. Philos Public Aff 1981;10:121-45.

33. Steinbock B. Coercion and long-term contraceptives. Hastings Cent Rep 1995;25 S19-22.

34. Nelson RM, Beauchamp T, Miller VA, et al. The concept of voluntary consent. Am J Bioeth 2011;11:6-16.

35. Foddy B, Savulescu J. Addiction and autonomy: can addicted people consent to the prescription of their drug of addiction. Bioethics 2006:20:1-15.

36. Foddy B, Savulescu J. A liberal account of addiction. Philos Psychiatr Psychol 2010;17:1-22

Advancing Postgraduates. Enhancing Healthcare.

The Postgraduate Medical Journal is dedicated to advancing the understanding of postgraduate medical education and training

- Acquire the necessary skills to deliver the highest possible standards of patient care

- Develop suitable training programmes for your trainees

- Maintain high standards after training ends

Published on behalf of the fellowship for Postgraduate Medicine

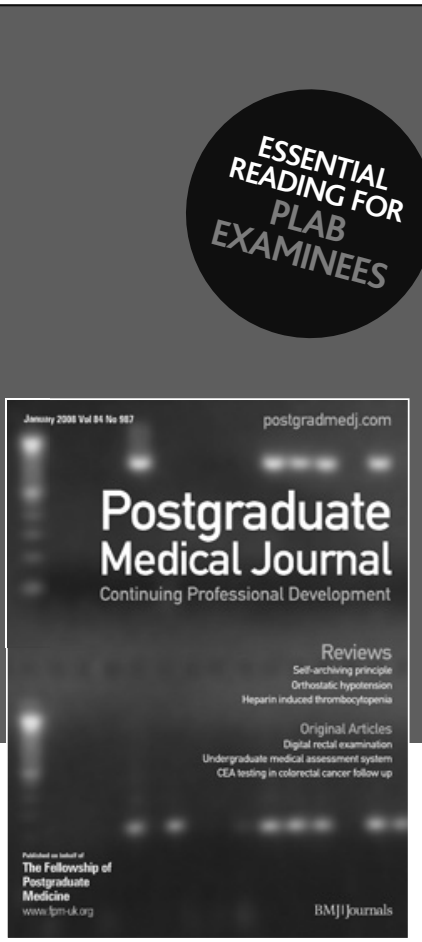

FOR MORE DETAILS OR TO SUBSCRIBE,

VISIT THE WEBSITE TODAY

\section{postgradmedj.com}

